\title{
Optimization of Aeration Technique for the Reduction of Impurities (Corrosive Gases) from Biogas.
}

\author{
S. M. A. Sujan*, M. S. Bashar, M. Rahaman, M. N. Haque, M. Y. Miah, M. S. Jamal, S. K. Banik \\ Institute of Fuel Research and Development (IFRD), Bangladesh council of Scientific and Industrial Research, \\ Dr. Qudrat-I-Khuda Road, Dhaka-1205, Bangladesh
}

\begin{abstract}
Biogas, produced from organic waste through anaerobic digestion (AD), is mainly composed of methane $\left(\mathrm{CH}_{4}\right)$ and carbon dioxide $\left(\mathrm{CO}_{2}\right)$ with smaller amount of hydrogen sulfide $\left(\mathrm{H}_{2} \mathrm{~S}\right)$ and nitrogen $\left(\mathrm{N}_{2}\right)$. Trace amount of some other gases are occasionally present in biogas. For electricity generation from biogas, reduction of $\mathrm{H}_{2} \mathrm{~S}$ is necessary because it is toxic and corrosive to most of the equipments. Reduction of Hydrogen Sulfide $\left(\mathrm{H}_{2} \mathrm{~S}\right)$ from poultry based biogas (normally it contents 1500 2500 ppm) can be done by dosing air/oxygen to the main digester during the digestion process. Two methods of air injection technique have been followed for optimization of the process. Firstly two hour interval air injection and secondly air injection based on percentage of hourly gas production. The optimum air percentage to minimize $\mathrm{H}_{2} \mathrm{~S}$ should be at least 3.00\%. After aeration $\mathrm{H}_{2} \mathrm{~S}$ level comes to the desired level (<50ppm) within 1.5-2.0 hours and remains constant up to 7-9 hours and biogas can be used for effective power generation. A complete aeration system has been developed which is simple and cost effective for $\mathrm{H}_{2} \mathrm{~S}$ reduction to the desired level from poultry based biogas plant. This system can be applied for any size of poultry based biogas plant for effective power generation.
\end{abstract}

Key words: Anaerobic digestion, Hydrogen Sulfide $\left(\mathrm{H}_{2} \mathrm{~S}\right)$, Aeration, Biogas digester, Power generation

\section{Introduction}

Biogas consists mainly of methane $\left(\mathrm{CH}_{4}\right)$ and carbon dioxide $\left(\mathrm{CO}_{2}\right)$, with smaller amounts of water vapor and trace amounts of hydrogen sulfide $\left(\mathrm{H}_{2} \mathrm{~S}\right)$, and other impurities. Various degrees of gas processing are necessary depending on the desired gas utilization process. Hydrogen sulfide is typically the most problematic contaminant because it is toxic and corrosive to most equipment (jerry 2008). Additionally, combustion of $\mathrm{H}_{2} \mathrm{~S}$ leads to sulfur dioxide emissions, which have harmful environmental effects. Removing $\mathrm{H}_{2} \mathrm{~S}$ as soon as possible is recommended to protect downstream equipment, increase safety, and enable possible utilization of more efficient technologies such as gas generator and micro turbines. Generally biogas has the following composition shown in Table I (Haque, S. M. et al., 2001).

Bangladesh has a great potential for biogas production in respect of the availability of raw materials and climatic conditions. There are more than 0.1 million poultry farms in Bangladesh from which 191 million cube meter biogas can be produced which can be used for power generation (Khandelwal K.C. and Mahdi S.S., 1993). But biogas from poultry farms contains more $\mathrm{H}_{2} \mathrm{~S}$ which is corrosive for engine. For better engine operation it needs to minimize $\mathrm{H}_{2} \mathrm{~S}$ level below 50 ppm.

Table I: Biogas composition and contaminants

\begin{tabular}{l|l}
\hline Major Component & \\
\hline Methane $\left(\mathrm{CH}_{4}\right)$ & $60-70 \%$ \\
Carbon dioxide $\left(\mathrm{CO}_{2}\right)$ & $30-40 \%$ \\
Nitrogen $\left(\mathrm{N}_{2}\right)$ & $1.0-1.5 \%$ \\
Oxygen $\left(\mathrm{O}_{2}\right)$ & $0.1-1.5 \%$ \\
Hydrogen $\left(\mathrm{H}_{2}\right)$ & $1.3-1.7 \%$ \\
Hydrogen $\mathrm{Sulfide}\left(\mathrm{H}_{2} \mathrm{~S}\right)$ & $1500-2500 \mathrm{ppm}$ \\
Mercaptanes & $0-100 \mathrm{ppm}$ \\
\hline Trace components & \\
\hline Siloxane & $0-100 \mathrm{mg} / \mathrm{m}^{3}$ \\
Halogenated Hydrocarbon & $0-100 \mathrm{mg} / \mathrm{m}^{3}$ \\
Moisture & Trace \\
\hline
\end{tabular}

The most common commercial methods for $\mathrm{H}_{2} \mathrm{~S}$ removal are, Air/oxygen dosing to digester biogas, Iron-chloride dosing

* Corresponding author: E-mail: asad2306@yahoo.com 
to digester slurry, Iron sponge, Iron oxide pellets, Activated carbon, Water scrubbing, $\mathrm{NaOH}$ scrubbing, Biological removal on a filter bed, Air stripping and recovery. The simplest method of the desulphurization is the addition of air/oxygen directly into the digester or in a storage tank serving at the same time as gas holder. Air is carefully admitted to the digester or biogas storage tank at levels corresponding to $2-6 \%$ air in biogas. It is believed effectiveness is based on biological aerobic oxidation of $\mathrm{H}_{2} \mathrm{~S}$ to elemental sulfur and sulfates. Inoculation is not required, as Thiobacillus species are naturally occurring at aerobic liquid-manure-wetted surfaces (Steven, 2003). Depending on the temperature, the reaction time, the amount and place of the air added the hydrogen sulfide concentration can be reduced by $95 \%$ to less than $50 \mathrm{ppm}$.

\section{Table II: Physical, Chemical and Safety Characteristics of Hydrogen Sulfide}

\begin{tabular}{l|l}
\hline Characteristics & Property \\
\hline Molecular Weight & 34.08 \\
Specific Gravity (relative to air) & 1.192 \\
Auto Ignition Temperature & $250^{\circ} \mathrm{C}$ \\
Explosive Range in Air & 4.5 to $45.5 \%$ \\
Odor Threshold & $0.47 \mathrm{ppb}$ \\
8-hour time weighted average & \\
(TWA) (OSHA) & $10 \mathrm{ppm}$ \\
15-minute short term exposure limit & \\
(STEL) (OSHA) & $15 \mathrm{ppm}$ \\
Immediately Dangerous to Life of & \\
Health (IDLH) (OSHA) & $300 \mathrm{ppm}$ \\
\hline
\end{tabular}

Source: OSHA (2002), Occupational Safety and Health Administration, www.OSHA.gov

The main objectives of this research work is to optimize aeration technique to reduce $\mathrm{H}_{2} \mathrm{~S}$ from poultry based biogas, to estimate the percentage of Hydrogen sulfide in biogas and optimization of injected air and time interval suitable for electricity generation.

\section{Experimental Methodology}

Necessary arrangement for biogas production and aeration system in the laboratory has been set up. For field level experiment one existing biogas plant $\left(1.27 \mathrm{~m}^{3}\right.$ gas production/day) of IFRD has been repaired and aeration arrangement has been established (Fig. 1). The plant has been charged by poultry dropping with necessary water mix and the gas analysis has been started after sufficient gas production. There are two sets of aeration technique have been followed in this experiment. i) Two hour interval air injection and ii) Air injection based on percentage of gas production. Collection of sample and analyze through Orsat analyzer and Gas analyzer. Optimization of injected air amount and time interval is based on analysis.

With a view to reducing $\mathrm{H}_{2} \mathrm{~S}$ from poultry based biogas plant for electricity generation, a complete air injection arrangement system in biogas plant has been developed and setup which shown in Figure 1 given below-

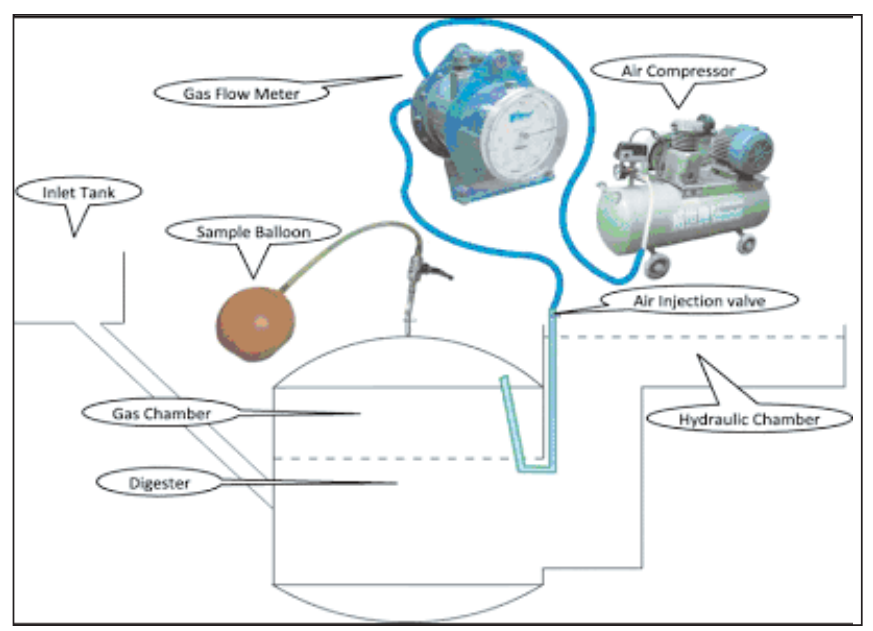

Fig. 1: Aeration arrangement for $\mathrm{H}_{2} \mathrm{~S}$ reduction

\section{Test procedure for $\mathrm{H}_{2} \mathrm{~S}$ reduction}

\section{Technique A}

Two hour interval air injection into the plant according to the following schedule shown in Table III.

Table III: Aeration schedule for $\mathrm{H}_{2} \mathrm{~S}$ reduction

\begin{tabular}{l|l|l}
\hline Time & Steps & Activity \\
\hline 9:40 & 1st Step & Test biogas composition \\
9:50 & 2nd Step & Vent out biogas from the plant \\
9:55 & 3rd Step & Inject 5.33 liter air \\
10:00 & 4th Step & Test biogas composition \\
12:00 & 5th Step & Test biogas composition \\
12:00 & 6th Step & Inject 5.33 liter air \\
12:05 & 7th Step & Test biogas composition \\
14:00 & 8th Step & Test biogas composition \\
14:00 & 9th Step & Inject 5.33 liter air \\
14:05 & 10th Step & Test biogas composition \\
16:00 & 11th Step & Test biogas composition \\
16:05 & 12th Step & Vent out biogas from the plant \\
16:10 & 13th Step & inject 5.33 liter air \\
\hline
\end{tabular}


During this experiment the gas production rate on an average was found 39.85 liter per hour which shown in Graph-1.

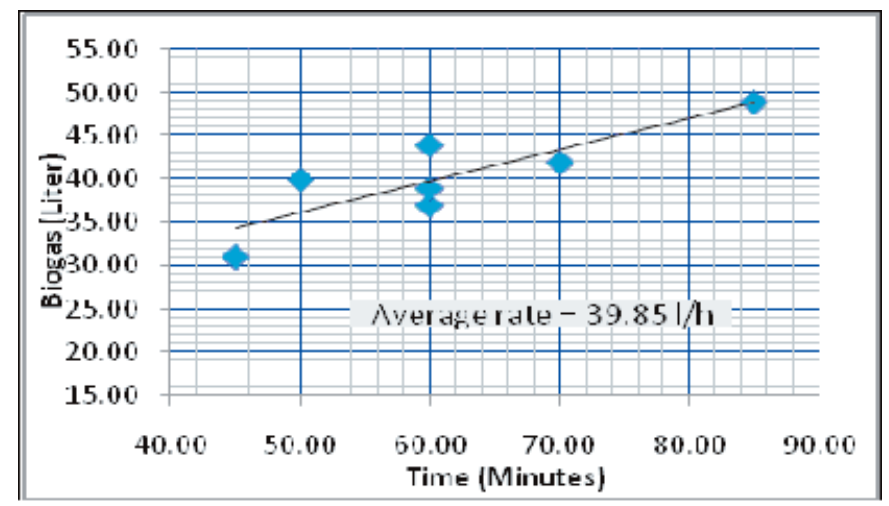

Graph 1: Gas production rate

$\mathrm{H}_{2} \mathrm{~S}$ reduction has been obtained by addition air at two hours interval which has shown in Table IV.

Table IV: Two hours interval aeration $\mathrm{H}_{2} \mathrm{~S}$ reduction

\begin{tabular}{l|r|r|r}
\hline Time & Air $(1)$ & Biogas $(1)$ & $\mathrm{H}_{2} \mathrm{~S}(\mathrm{ppm})$ \\
\hline 10:05 AM & 5.26 & 0.00 & $>500$ \\
10:15 AM & & 3.40 & $>500$ \\
12:00 PM & & 35.70 & 106.00 \\
12:00 PM & 5.30 & 0.00 & \\
12:10 PM & & 3.40 & 71.00 \\
2:00 PM & & 37.40 & 18.00 \\
2:00 PM & 5.20 & 0.00 & \\
2:10 PM & & 3.40 & 9.00 \\
4:00 PM & & 37.40 & 3.00 \\
\hline
\end{tabular}

Single Air injection based on percentage of gas production.

\section{Technique B}

During experiment, the plant was in continuous charging condition and the gas production rate has been found to be 50.50 liter per hour shown in the Graph 2.

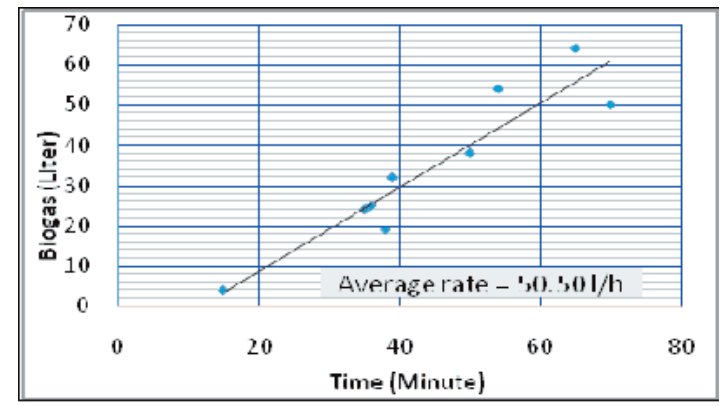

Graph 2: Gas production rate
Significant $\mathrm{H}_{2} \mathrm{~S}$ reduction have been achieved by addition of air to biogas and time needs to reduce initial level down to below 50 ppm is about 1 hour and 20 minutes shown in the Graph 3.

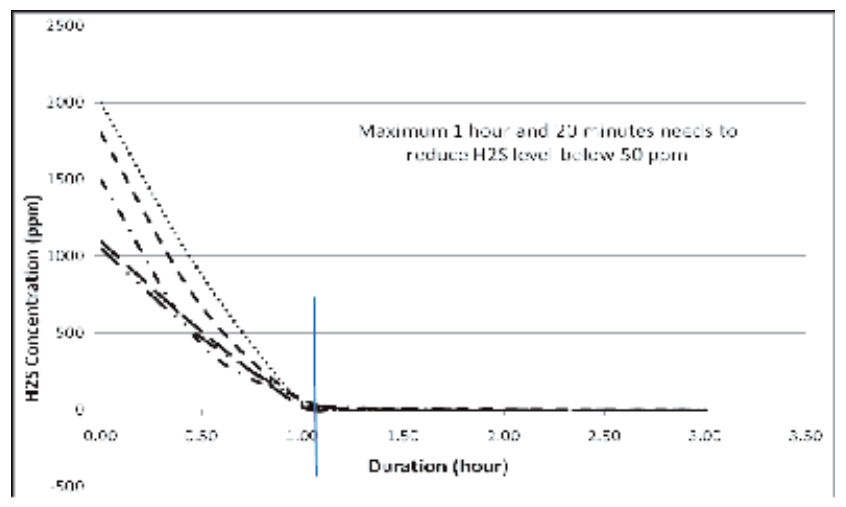

Graph 3: Time to reduce $\mathrm{H}_{2} \mathrm{~S}$

The duration to remain $\mathrm{H}_{2} \mathrm{~S}$ concentration under the desired level varies with addition of different percentage of air to biogas in the plant which are shown in the Graph 4.

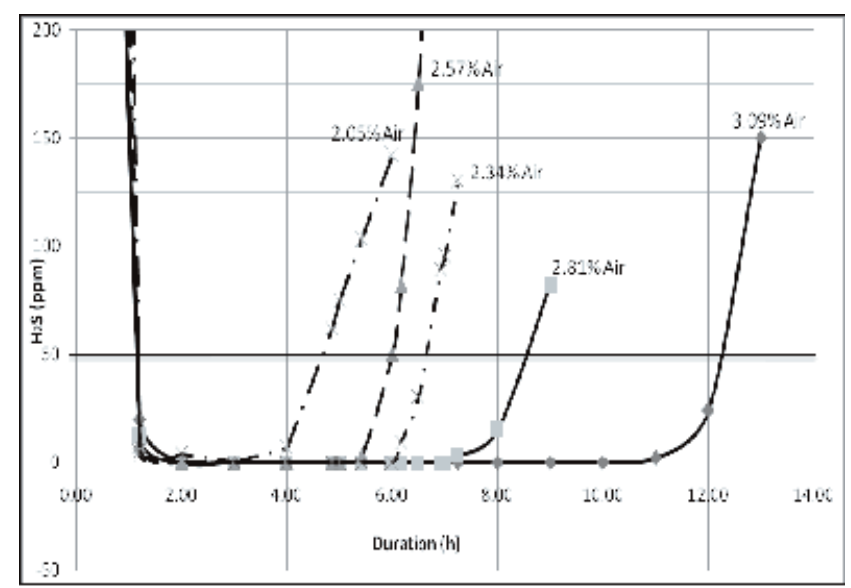

Graph 4: Duration of below desired level of $\mathrm{H}_{2} \mathrm{~S}$ by aeration with different percentage of air

Biogas composition of experimental poultry based biogas plant before and after aeration system has been determined and shown in the Table V.

Table V: The composition of biogas before and after aeration

\begin{tabular}{l|c|c|c}
\hline S/N & Component & Before aeration & After aeration \\
\hline 1. & $\mathrm{CH}_{4}$ & $68.40 \%$ & $66.50 \%$ \\
2. & $\mathrm{CO}_{2}$ & $27.80 \%$ & $26.20 \%$ \\
3. & $\mathrm{H}_{2} \mathrm{~S}$ & $1850 \mathrm{ppm}$ & $<50 \mathrm{ppm}$ \\
4. & $\mathrm{O}_{2}$ & $0.80 \%$ & $1.80 \%$ \\
5. & $\mathrm{~N}_{2}$ & $2.10 \%$ & $4.80 \%$ \\
\hline
\end{tabular}




\section{Results and Discussion}

Throughout the research, there are two techniques have been applied for $\mathrm{H}_{2} \mathrm{~S}$ reduction from poultry based biogas.

In Technique A, two hour interval air injection into the plant has been carried out according to the schedule shown in Table I. At that time, gas production rate was 39.85 liter per hour (shown in Graph 1). From the Table II, it was found that $\mathrm{H}_{2} \mathrm{~S}$ level reduced up to minimum $(<50 \mathrm{ppm})$ after four hours of initial air injection.

In Technique B, single air injection has been carried out based on percentage of gas production. During experiment, the plant was in continuous charging condition and the gas production rate has been found around 50.50 liter per hour (Shown in Graph 2). Significant $\mathrm{H}_{2} \mathrm{~S}$ reduction has been achieved by addition of different percentage of air (2.05$3.09 \%$ ) to biogas plant which are shown in the Graph 3. From the Graph 3 it is found that the duration of the $\mathrm{H}_{2} \mathrm{~S}$ level remains minimum depending on the percentage of air injection. At this percentage of air, $\mathrm{H}_{2} \mathrm{~S}$ level comes to the desired level $(<50 \mathrm{ppm})$ within 1.5-2.0 hours and remains constant up to 7-9 hours and biogas can be used for effective power generation.

Finally the Table IV shows that $\mathrm{H}_{2} \mathrm{~S}$ concentration in poultry based biogas has been found to be $1850 \mathrm{ppm}$ to less than 50 ppm before and after aeration respectively.

\section{Conclusion}

Generally $\mathrm{H}_{2} \mathrm{~S}$ concentration in poultry based biogas varies from 1500-2500 ppm. A complete aeration system has been developed which is simple and cost effective for $\mathrm{H}_{2} \mathrm{~S}$ reduction to the desired level from poultry based biogas plant. The optimum air percentage to minimize $\mathrm{H}_{2} \mathrm{~S}$ should be at least $3.0 \%$. After aeration $\mathrm{H}_{2} \mathrm{~S}$ level comes to the desired level $(<50 \mathrm{ppm})$ within 1.5-2.0 hours and remains constant up to 79 hours and biogas can be used for effective power generation. This system can be applied for any size of poultry based biogas plant for effective power generation.

Compare with the chemical treatment (Haque et al., 2001) the developed technique is cheaper, easier and user friendly for reduction of Hydrogen Sulfide from biogas.

\section{Acknowledgements}

Foremost, Authors would like to express our sincere gratitude to Mr. Jasim Uddin Chowdhury, director IFRD, BCSIR, Dhaka for his continuous support and encouragement for carrying out this research work.

Authors would like to thank German Technical Cooperation (gtz) for financial support to complete this research project.

Besides this, Authors would like to thank laboratory technicians K. M. Abul Kalam, Md. Nasu Miah, Md. Mozzammel Hossain and Md. Abdul Hamid for their sincere assistance.

\section{References}

Haque S. M., Haque N. M. and Miah Y. M. (2001). Reduction of Carbon dioxide and elimination of Hydrogen Sulfide from Biogas. Bangladesh J. Sci. \& Tec. 3(2): 293-300.

Jerry H. M. (2008). A New Method to Evaluate Hydrogen Sulfide Removal from Biogas, MS thesis, pp-07, North Carolina State University, USA.

Khandelwal K. C. and Mahdi S. S. (1993) A Practical Handbook Volume I "Biogas Technology" 5th reprint (Tata McGraw-Hill Publishing Company Limited, New Delhi) 1986, pp-13.

OSHA (2002). Occupational Safety and Health Administration Hazardous Pollutants List. U.S. Department of Labor, Washington, D.C. www.OSHA.gov.

Steven Mc. Z. (2003). Removal of Hydrogen Sulfide from Biogas using Cow-Manure compost. MS Thesis, pp106, Cornell University, United Kingdom.

Received : April 04, 2010;

Accepted : January 11, 2011 